\title{
Simulation of Power and Particle Flows in the NSTX Edge Plasma
}

M.E. Rensink, H. Kugel, R. Maingi, F. Paoletti, G.D. Porter, T.D. Rognlien, S. Sabbagh, X.Q. Xu

This article was submitted to $14^{\text {th }}$ International Conference on Plasma Surface Interactions (PSI), Rosenheim, Germany, May 22-26, 2000

\section{May 18, 2000}

Lawrence

Livermore

National

Laboratory 


\section{DISCLAIMER}

This document was prepared as an account of work sponsored by an agency of the United States Government. Neither the United States Government nor the University of California nor any of their employees, makes any warranty, express or implied, or assumes any legal liability or responsibility for the accuracy, completeness, or usefulness of any information, apparatus, product, or process disclosed, or represents that its use would not infringe privately owned rights. Reference herein to any specific commercial product, process, or service by trade name, trademark, manufacturer, or otherwise, does not necessarily constitute or imply its endorsement, recommendation, or favoring by the United States Government or the University of California. The views and opinions of authors expressed herein do not necessarily state or reflect those of the United States Government or the University of California, and shall not be used for advertising or product endorsement purposes.

This is a preprint of a paper intended for publication in a journal or proceedings. Since changes may be made before publication, this preprint is made available with the understanding that it will not be cited or reproduced without the permission of the author.

This report has been reproduced

directly from the best available copy.

Available to DOE and DOE contractors from the

Office of Scientific and Technical Information

P.O. Box 62, Oak Ridge, TN 37831

Prices available from (423) 576-8401

http://apollo.osti.gov/bridge/

Available to the public from the

National Technical Information Service

U.S. Department of Commerce

5285 Port Royal Rd.,

Springfield, VA 22161

http://www.ntis.gov/

OR

Lawrence Livermore National Laboratory

Technical Information Department's Digital Library

http://www.llnl.gov/tid/Library.html 


\title{
Simulation of Power and Particle Flows in the NSTX Edge Plasma
}

\author{
M. E. Rensink, H. Kugel(a), R. Maingi(b), F. Paoletti(c), \\ G. D. Porter, T. D. Rognlien, S. Sabbagh(c), X. Q. Xu \\ Lawrence Livermore National Laboratory, P. O. Box 808, Livermore, CA 94551 \\ (a) Princeton Plasma Physics Laboratory, Princeton, NJ \\ (b) Oak Ridge National Laboratory, Oak Ridge, TN \\ (c) Columbia University, New York, NY
}

\begin{abstract}
We simulate edge plasmas in NSTX double-null divertor configurations with the UEDGE two-dimensional fluid code. The carbon impurity density in the core plasma and total radiated power increase with the core heating power and the magnitude of the physical and chemical sputtering in the divertor. Up/down plasma asymmetries are generated by classical cross-field particle drifts. With the standard toroidal magnetic field direction (ion $\nabla B$ drift toward the lower $x$-point) the highest density occurs at the lower inboard divertor plate and the highest heat flux at the upper outboard divertor plate. Simulations of 3-d edge plasma turbulence with the BOUT code show that anomalous radial transport at the outboard midplane should be similar in magnitude for NSTX and DIII-D.
\end{abstract}

\section{Introduction}

Core plasma confinement in a tokamak is strongly correlated with properties of the edge plasma. In this report we present results of edge plasma simulations for NSTX in double null divertor configurations. The simulations use the UEDGE two-dimensional fluid code [1]. Experimental measurements of the edge plasma in NSTX are not yet comprehensive enough to make meaningful comparisons with the simulation, but the simulation results should be a reliable guide to edge plasma behavior because the UEDGE code has been extensively benchmarked against several other tokamak devices. For the first series of simulations in this report we examine the global properties of the edge plasma as a function of the total heating power into the plasma and the sputtering yield at the plasma-facing surfaces in the divertor. A second series of simulations takes a look at up/down asymmetries due to classical cross-field drifts. Finally, we test the assumption of similar anomalous radial transport in NSTX and DIII-D with simulations of these configurations using the BOUT 3-d fluid turbulence code [2].

\section{Model}

The UEDGE code solves for the density, temperature and flow velocity of the plasma and neutrals in the edge region near the separatrix, as illustrated in Fig. 1. The simulation mesh is based on flux surfaces from MHD equilibria calculated by the EFIT code. The steady state solutions depend on the boundary conditions and the transport models for both plasma and neutrals. The model assumes classical plasma transport along field lines and spatially uniform anomalous radial transport coefficients whose values are derived from benchmarking with DIII-D data. We specify fixed plasma density at the innermost core flux surface of the mesh, and recycling boundary conditions for hydrogenic plasma at the walls and divertor plates. Physical and chemical sputtering at the carbon divertor plates and radial mesh boundaries are modeled by a modified form of the sputtering yields given by Haasz and Davis [3] with reduced yield at low ion impact energies. The total heating 
power is specified in terms of the total electron and ion power crossing the innermost core flux surface. The ion and electron temperatures at the outer walls are fixed at $2 \mathrm{eV}$; in the private flux regions we specify zero heat flux.

\section{Sputtering}

We investigate the expected radiated power and the flow of intrinsic (carbon) impurities to the closed flux surfaces as a function of the sputtering yield and total heating power. For this series of simulations we assume up/down symmetric plasmas, consistent with a magnetically balanced double-null configuration and negligible cross-field drifts. To examine the effect of uncertainty in the wall conditions, e.g., due to boronization, we introduce a scaling factor, $\mathrm{f}_{\text {Haasz }}$, for the sputtering yield relative to the Haasz and Davis model. Both physical and chemical sputtering yields are scaled by a common multiplicative factor. The variation of the radiation and core impurity content with this multiplicative factor is shown in Fig. 2. With $1 \mathrm{MW}$ of input power we find the total radiated power increases from $15 \%$ with no sputtering source to about $45 \%$ of the input power when the sputtering yield multiplier is increased to 0.6 ; the carbon density rises to $3 \%$ of the electron density in the core. At higher input powers, as shown in Fig. 3, the core carbon content increases to near $10 \%$ and may indicate a need for wall conditioning to control the sputtering source.

\section{Cross-Field Drifts}

$\mathrm{U}_{\mathrm{p}}$ /down plasma asymmetries in a double-null configuration can be due to magnetic imbalance, cross-field drifts and other factors. In this report we investigate the influence of cross-field drifts on the up/down plasma asymmetry for a magnetically balanced doublenull configuration in NSTX. These drifts have a strong effect in conventional single-null tokamaks [4] and may also be important in spherical tokamaks. Figures 4 and 5 compare simulations with and without cross-field drifts. The toroidal magnetic field direction is such that the ion $\nabla B$ drift is toward the lower x-point. In Fig. 4 the highest density occurs at the lower inboard plate; this is due to a significant $E \times B$ particle flux through the lower private flux region from the outboard to the inboard plates. In the upper divertor, the $E \times B$ particle flux is from the inboard to the outboard plate, so the density is higher at the outboard plate. The heat flux at the outboard plates is higher than at the inboard plates because most of the power enters the SOL through the outboard half of the separatrix. In this simulation, $85 \%$ of the total power flows to the outer SOL from the core. The maximum heat flux, 3.5 $\mathrm{MW} / \mathrm{m}^{2}$, occurs at the upper plate due to a convective heat flux component which correlates with higher density at the upper plate. At higher input power the effect of cross-field drifts will be even stronger due to higher electron temperatures and associated electric fields.

\section{Turbulence}

In our UEDGE modeling of the NSTX edge plasma we have chosen anomalous radial transport coefficients based on previous benchmarking with experimental data from DIII-D. This similarity assumption is tested by comparing 3-d simulations of edge plasma turbulence in NSTX and DIII-D using the BOUT code. Simulations in the two magnetic configurations are run with a common plasma background from UEDGE. We find that turbulent fluctuation levels, $\tilde{n} / n$, at the outboard midplane are slightly higher in NSTX than in DIII-D. Also, the turbulence at the midplane extends radially over a somewhat larger region of the edge plasma, but the eddy size of the fluctuating density is about three times larger on DIII-D than on NSTX at the midplane. The net result is that the anomalous radial diffusivity for particles and energy at the midplane is similar $\left(\sim 1 \mathrm{~m}^{2} \mathrm{sec}^{-1}\right)$ in DIII-D and NSTX, but with significant spatial variation. 


\section{Acknowledgements}

This work was performed under the auspices of the U.S. Department of Energy by University of California Lawrence Livermore National Laboratory under contract No. W-7405-Eng-48.

\section{References}

[1] T. D. Rognlien, et al., Contr. Plasma Phys. 34 (1994) 362

[2] X. Q. Xu, et al., Nuclear Fusion 40 (2000) pp.

[3] J. W. Davis and A. A. Haasz, J. Nucl. Mater. 241-243 (1997) 37.

[4] T. D. Rognlien, et al., Phys. Plasmas 6 (1999) 1851.

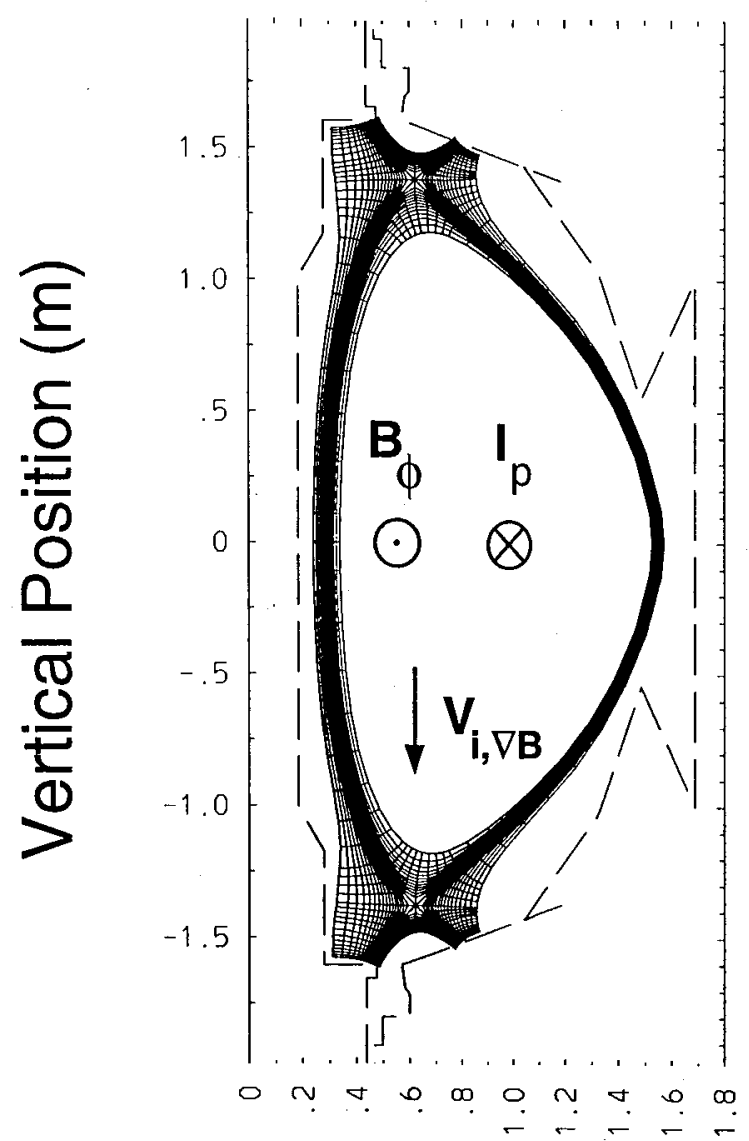

Radial Position (m)

Figure 1: The (orthogonal) edge-plasma mesh for simulation of NSTX balanced double-null configurations. 

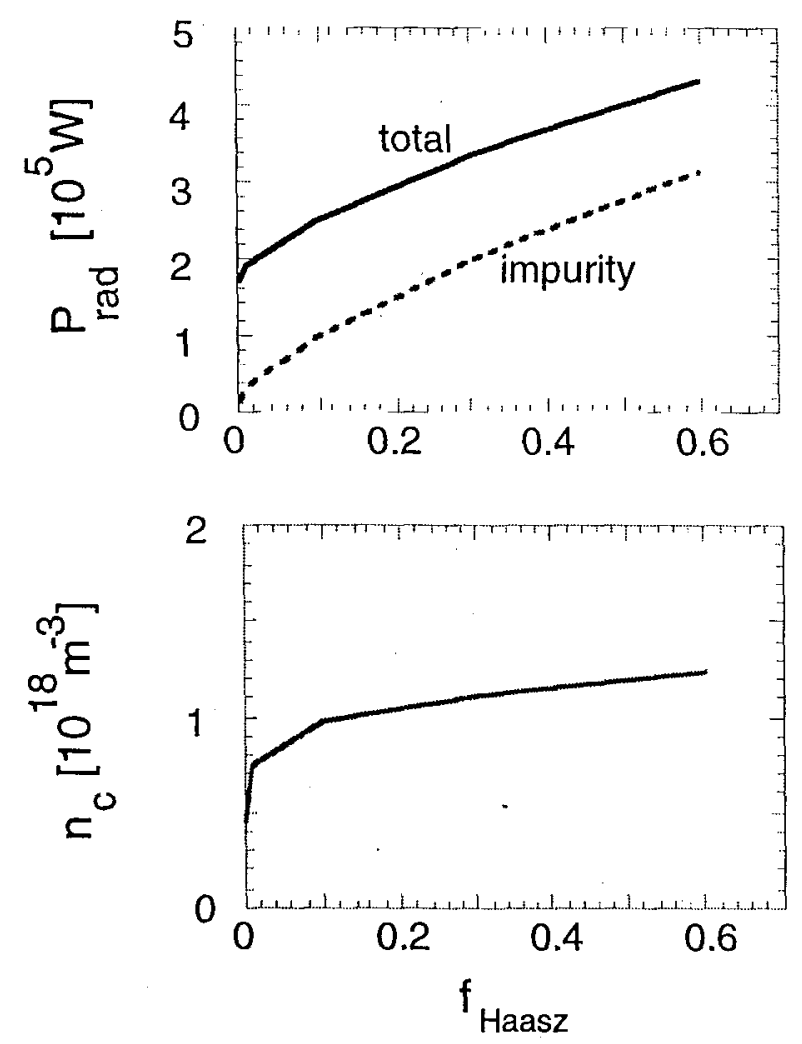

Figure 2: Variation of total radiated power and core carbon density with carbon sputtering yield factor. Heating power is $1 \mathrm{MW}$ and core plasma density is $4 \times 10^{19} \mathrm{~m}^{-3}$. 

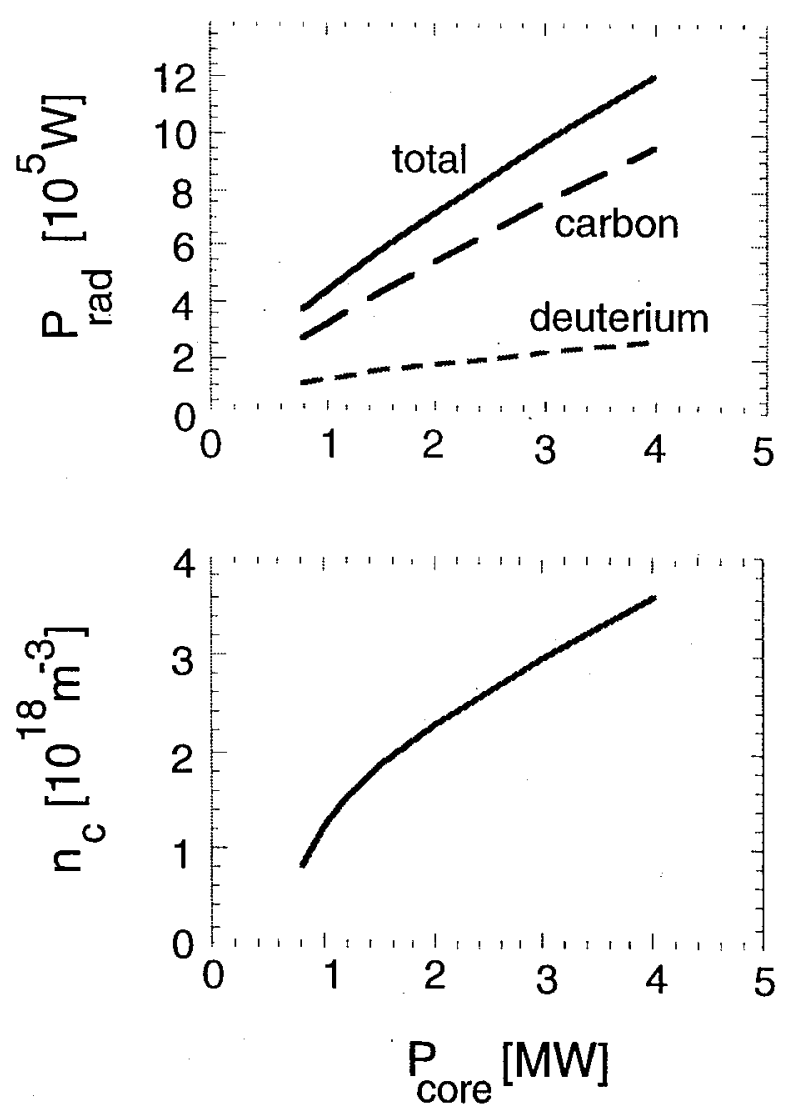

Figure 3: Variation of total radiated power and core carbon density with heating power. The carbon sputtering yield factor is 0.6 and core plasma density is $4 \times 10^{19} \mathrm{~m}^{-3}$. 

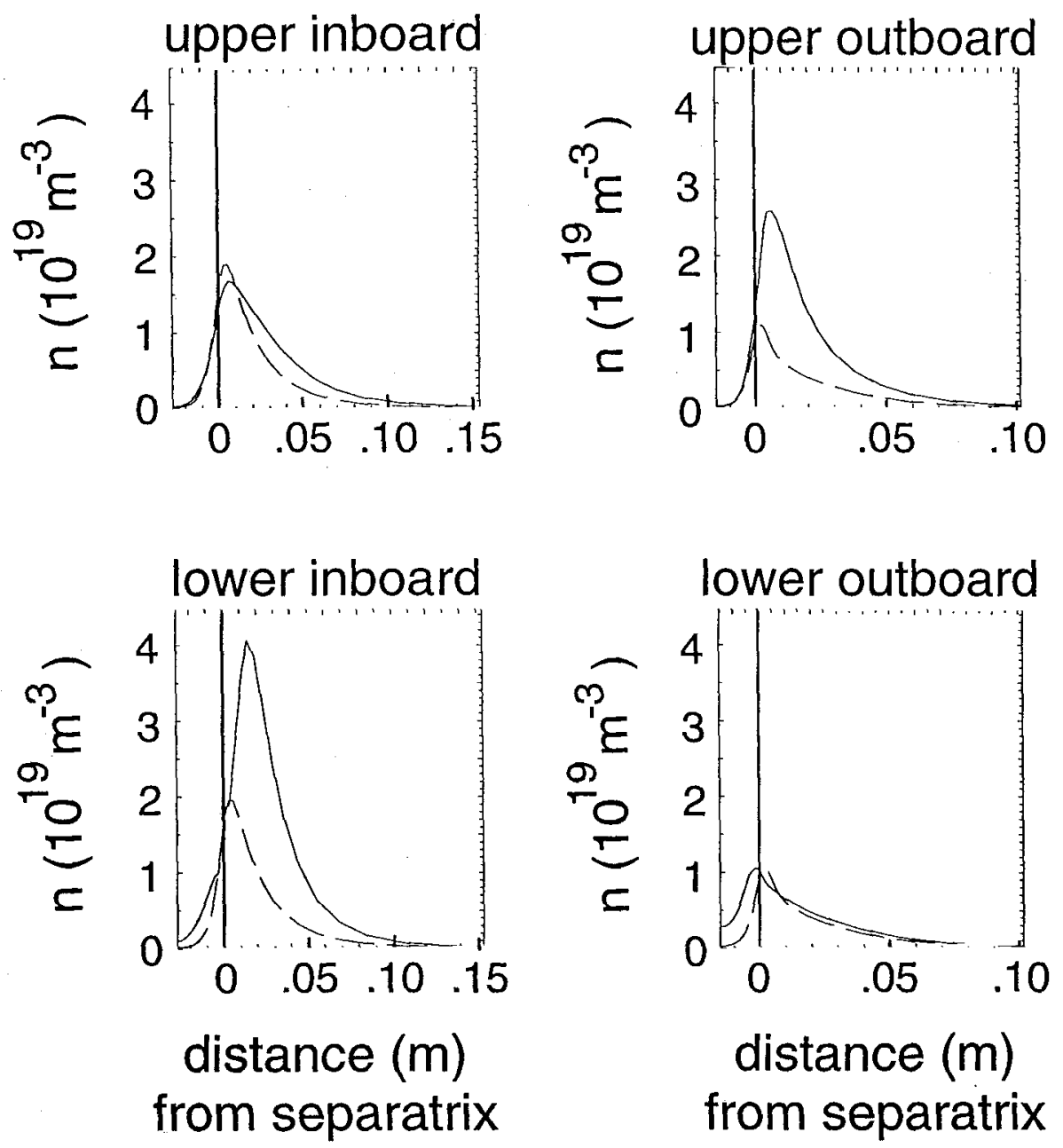

Figure 4: The radial profiles of the plasma density on the divertor plates for a magnetically balanced NSTX double-null configuration. The total input power to the SOL is $1 \mathrm{MW}$ and the core plasma density is $3 \times 10^{19} \mathrm{~m}^{-3}$. The solid curve includes cross-field drifts. The dashed curve does not. 

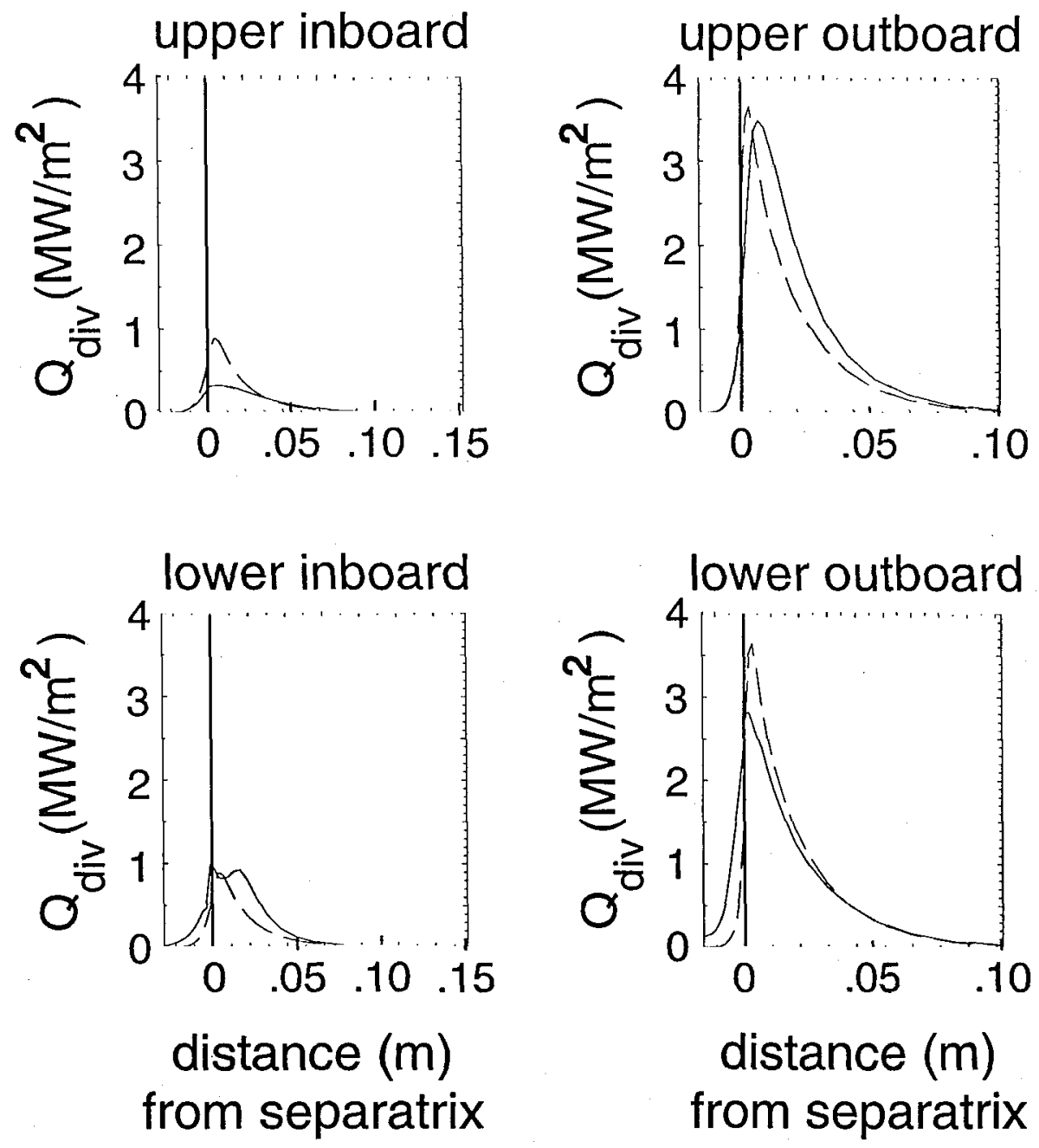

Figure 5: The radial profiles of the heat flux on the divertor plates for a magnetically balanced NSTX double-null configuration. The total input power to the SOL is $1 \mathrm{MW}$ and the core plasma density is $3 \times 10^{19} \mathrm{~m}^{-3}$. The solid curve includes cross-field drifts. The dashed curve does not. 